\section{Prevalence of blindness and low vision in an Italian population: a comparison with other European studies} studies
C Cedrone ${ }^{1}$, C Nucci ${ }^{1}$, G Scuderi ${ }^{2}$, F Ricci $^{1}$, A Cerulli ${ }^{1}$ and $\mathrm{F}$ Culasso ${ }^{3}$

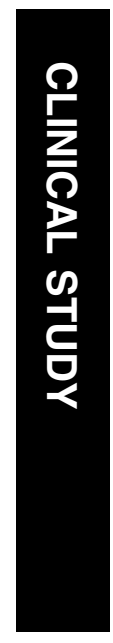

\begin{abstract}
Aim The scientific literature contains recent data on the prevalence of blindness and low vision for a few European countries, but most of these studies have been focused exclusively on the elderly sector of the populations. The purpose of the present study was to provide age-specific estimates of the prevalence and causes of visual loss in an Italian population aged 40 years and over.

Methods In total, 847 of the 1200 citizens $>40$ years of age $\mathbf{( 7 0 . 6 \% )}$ in the island community of Ponza underwent complete standardized ophthalmological examinations. Visual acuity (VA) was measured using a standard logarithmic chart. World health organization (WHO) definitions of blindness and low vision were adopted (respectively, VA $>1.3$ $\log$ MAR or a visual field $<10^{\circ}$ around central fixation, and VA $>0.5$ to $1.3 \log$ MAR or a visual field $<20^{\circ}$ around central fixation). Prevalence rates based on presenting VAs were also calculated.

Results The overall best-corrected prevalence rates were $0.6 \%$ (presenting, $0.8 \%$ ) for better eye blindness, $2.1 \%$ (presenting, 6.7\%) for better eye low vision, $1.8 \%$ (presenting, $2.6 \%$ ) for monocular blindness, $5.0 \%$ (presenting, $\mathbf{1 1 . 2 \%}$ ) for monocular low vision. Cataract, glaucoma, degenerative myopia, and AMD were the main causes of better eye visual loss. Conclusion Age-specific prevalence rates in Ponza are fairly consistent with those for other European countries with similar socioeconomic conditions and public healthcare systems. A substantial percentage of visual losses remains uncorrected despite the availability of potentially curative therapy.
\end{abstract}

Greater emphasis needs to be placed on educating the public regarding the importance of good vision.

Eye (2006) 20, 661-667. doi:10.1038/sj.eye.6701934; published online 27 May 2005

Keywords: blindness; low vision; prevalence; adult

\section{Introduction}

The most recent figures in the World Health Organization (WHO) database reveal a prevalence of blindness among adults in Europe ranging from $0.2 \%$ in France (1985) to $0.7 \%$ in the United Kingdom (1991). ${ }^{1}$ For many countries, the WHO figures are based on data collected over 15 years ago, and the current situation may be worse as a result of population ageing. The scientific literature contains more recent data for a few European countries (Finland, ${ }^{2}$ The Netherlands, ${ }^{3}$ Denmark, ${ }^{4,5}$ and The United Kingdom ${ }^{6-8}$ but most of these studies have been focused exclusively on the elderly sectors of the populations (60-80 years in Denmark, ${ }^{4,5} 65$ and over in two of the UK studies, 7,870 and over in Finland, ${ }^{2}$ and 75 and over in the third UK study. ${ }^{6}$ The youngest sample, 55 years and over, has been examined in The Netherlands. ${ }^{3}$

Based on findings from recent populationbased studies and National Household Health Surveys (NHHS), the estimated prevalence of blindness in Italy is approximately 0.5 and $1 \%$ for low vision, for a total of almost 850000 visually impaired persons. ${ }^{9-12}$ During the last NHHS (1999-2000), ${ }^{12}$ approximately 140000 persons from more than 52000 households were asked if they were capable of seeing and
${ }^{1}$ Physiopathological Optics, Department of Biopathology and Diagnostic Imaging, University of Rome 'Tor Vergata', Rome, Italy

${ }^{2}$ Eye Clinic, Sant'Andrea Hospital, University of Rome 'La Sapienza', Rome, Italy

${ }^{3}$ Medical Statistics, Department of Experimental Medicine, University of Rome 'La Sapienza', Rome, Italy

Correspondence: C Cedrone, Cattedra di Ottica Fisiopatologica, Dipartimento di Biopatologia e Diagnostica per Immagini, Università degli Studi di Roma 'Tor Vergata', Via Montpellier 1, 00133 Roma, Italy Fax: + 39062026232

E-mail: cedrone@ uniroma2.it

Received: 1 July 2004 Accepted in revised form: 12 April 2005 Published online: 27 May 2005 
recognizing a friend at a distance of $4 \mathrm{~m}$ with the corrective lenses they normally used (if such lenses were used). If the reply was negative (indicating significant visual loss), the question was repeated for a distance of one meter. Based on negative responses to the latter question, the self-reported rate of blindness, in this sample, was $0.6 \%$, and an additional $2.0 \%$ of the respondents admitted 'some difficulty' in recognizing a friend at this distance.

The present study was designed to provide agespecific estimates of the prevalence and principal causes of blindness and low vision in an Italian population aged 40 years and over, and to make a comparison with other European studies.

\section{Materials and methods}

In 1988, complete standardized ophthalmologic exams were performed on the residents of the municipality of Ponza, which includes the entire $7.3 \mathrm{~km}^{2}$ of the Island of Ponza, located 18 miles off the western coast of Italy. The recruitment and examination methods used in this study have been described in detail elsewhere. ${ }^{11}$

At 12 years after the completion of these baseline examinations, a follow-up study was conducted on the surviving members of the original adult cohort to determine the incidence of visual loss and other eye diseases. ${ }^{13}$ In an attempt to improve community acceptance of the initiative, and to gather up-dated findings on prevalence, the only eligibility requirements for participation in the 2000 study were (1) legal and actual residence in Ponza at the time of the examinations, that is, March-May 2000, and (2) age $\geqslant 40$ years on December 31, 1999.

Subjects who satisfied these criteria received a letter inviting them to take part in the study and describing the objectives and methods to be used. Those who failed to reply to the invitation or declined were considered 'unexplained refusals'. Those who accepted the invitation were contacted by phone to set up an appointment. Subjects who cancelled or missed their appointments were contacted by examiners to determine the reason for the cancellation, and if an alternative appointment could not be arranged, the patient was classified as a 'nonparticipant'. Those who actually took part in the study ('participants') were examined by the same ophthalmologist and the same orthoptist used in the 1988 study, using the same examination procedure, methods, and classification criteria. Informed written consent was obtained from all these participants.

Objective autorefraction examinations were administered by an orthoptist, who also recorded the patient history. Standardized ophthalmic examinations were performed by the ophthalmologist. All patients with suspected glaucoma (based on the following criteria: previous diagnosis of glaucoma, family history of glaucoma, shallow anterior chamber detected by the slit-lamp examination, IOP greater than $20 \mathrm{mmHg}$, cupto-disc ratio of 0.5 or greater, or difference in cup-to-disc ratio of 0.2 or more), patients with suspected hereditary retinal degenerations (based on previous diagnosis, family history, fundus appearance), and patients with reported sensation of reduced visual field underwent a Central 30-2 full threshold test with the Humphrey Field Analyzer for quantitative evaluation of the differential sensitivity in the central and paracentral areas. Defective areas were defined more completely based on retesting with a Custom Grid ( $2^{\circ}$ spacing).

Visual acuity (VA) was measured at a distance of $4 \mathrm{~m}$ as previously described using a standard 10-letter logarithmic chart designed according to the recommendations of the National Academy of SciencesNational Research Council. ${ }^{14}$ Visual loss was classified according to WHO recommendations as follows:

Blindness Best-corrected VA of $>1.3 \log$ MAR (equivalent of $<3 / 60$ or $<1 / 20$ or $<20 / 400$ ) or a visual field $<10^{\circ}$ around central fixation. (These criteria correspond to ICD-10 categories 3-5 of visual loss.)

Low vision Best-corrected VA of $>0.5$ to $1.3 \log$ MAR (equivalent of $<6 / 18$ to $3 / 60$ or $<3 / 10$ to $1 / 20$ or $<20 / 70$ to $20 / 400$ ) or a visual field $<20$ to $10^{\circ}$ around central fixation, (ICD-10 categories 1-2).

Binocular impairment was defined based on findings in the better eye; monocular impairment was classified according to VA in the affected eye (VA in the fellow eye being normal or near normal).

To identify possible discrepancies between the 'bestcase scenarios' based on best corrected VA and the actual 'operative visual status' of the population, we also calculated the prevalence rates based on presenting VA, that is, uncorrected acuity or that provided by the corrective lenses normally used by the patient for driving, work, and other activities of daily life.

The probable cause of visual loss (and, in cases of multiple eye diseases, the major contributor) was indicated on the subject's chart by the field examiner. These indications were subsequently reviewed by a panel of three clinical investigators. The final decisions were based on consensus judgement of the panel members following standardized examination of all data available for the patient and application of standard clinical criteria.

Confidence intervals for each prevalence percentage were calculated using the Poisson distribution for percentages less than $5 \%$ and a binomial distribution for percentages equal to or greater than $5 \%$. To identify correlation between visual loss and clinical or demographic risk factors - age $\geq 70$, female sex, unmarried status, $<6$ years of education, history of 
hypertension, diabetes, cholesterol, cardiovascular disease, current smoking status and alcohol consumption, myopia, glaucoma, cataract, diabetic retinopathy, AMD - the latter factors were first analyzed separately.

Those that emerged as significant were then included in a stepwise logistic regression to compute the regression coefficients (ie, ORs for the binary variables) adjusted for the other considered factors. Causes of visual loss were analyzed based on the number of subjects and on the number of eyes affected.

The significance of differences between prevalence rates found in our study and those reported in other populations was assessed with the $\chi^{2}$ test. In several of these studies visual losses were classified according to the system used to evaluate driver's license eligibility (US definitions), which is less restrictive than that of the WHO. For these comparisons, our results were recalculated using the US criteria.

\section{Results}

At the time of our examinations in 2000, there were 1200 officially registered citizens aged 40 years or over currently residing in Ponza (571 males and 629 females). In total, 140 (11.7\%) (61 males and 79 females) declined our invitation to take part in the study (unexplained refusals), and there was no significant difference between the numbers of males and females in this group. Of the remaining 1060 subjects, who made appointments for examinations, 847 (70.6\% of the 1200 eligible sample) were actually examined (participant group). The sample population included 401 male participants $(70.2 \%$ of the 571 eligible sample) and 446 female participants $(70.9 \%$ of the 629 eligible sample) $(P>0.10)$; similar $\mathrm{M} / \mathrm{F}$ ratios were found in all age groups. The other 213/1060 failed to keep their appointments (nonparticipant group). When contacted by our staff, the subjects justified their absence on the basis of problems related to personal health $(85 / 213 ; 39.9 \%)$, work $(68 / 213 ; 31.9 \%)$, or family responsibilities $(60 / 213 ; 28.2 \%)$. Reports of personal health problems increased with subject age (from $7 \%$ in the $40-49$ year group to $74 \%$ in the 80 years and over group).

Table 1 summarizes the overall and age-related prevalence rates for blindness and low vision based on best-corrected VAs. Figures are based on data for only 843 of the 847 participants because best-corrected VA

Table 1 Prevalence of blindness and low vision by gender and age in the Ponza 2000 Eye Study

\begin{tabular}{|c|c|c|c|c|c|c|c|c|c|c|c|c|c|}
\hline \multirow[t]{3}{*}{ Sex/age } & \multirow[t]{3}{*}{ Examined } & \multicolumn{6}{|c|}{ Better eye } & \multicolumn{6}{|c|}{ Monocular } \\
\hline & & \multicolumn{3}{|c|}{ Blindness } & \multicolumn{3}{|c|}{ Low vision } & \multicolumn{3}{|c|}{ Blindness } & \multicolumn{3}{|c|}{ Low vision } \\
\hline & & No. & $\%$ & $95 \% C I$ & No. & $\%$ & $95 \% \mathrm{CI}$ & No. & $\%$ & $95 \% C I$ & No. & $\%$ & $95 \% C I$ \\
\hline \multicolumn{14}{|l|}{ Males } \\
\hline 40-49 & 128 & 0 & 0.0 & $0.0-3.1$ & 0 & 0.0 & $0.0-3.1$ & 0 & 0.0 & $0.0-3.1$ & 4 & 3.1 & $1.3-8.2$ \\
\hline $50-59$ & 96 & 0 & 0.0 & $0.0-4.2$ & 0 & 0.0 & $0.0-4.2$ & 1 & 1.0 & $0.2-6.1$ & 2 & 2.1 & $0.6-7.9$ \\
\hline $60-69$ & 70 & 0 & 0.0 & $0.0-5.8$ & 0 & 0.0 & $0.0-5.8$ & 0 & 0.0 & $0.0-5.8$ & 3 & 4.3 & 0.9-10.9 \\
\hline $70-79$ & 82 & 0 & 0.0 & $0.0-4.9$ & 2 & 2.4 & $0.7-9.3$ & 5 & 6.1 & 2.9-14.8 & 11 & 13.4 & 5.1-19.3 \\
\hline $80+$ & 23 & 0 & 0.0 & $0.0-19.5$ & 5 & 21.7 & $4.9-38.6$ & 2 & 8.7 & $0.0-20.2$ & 1 & 4.3 & $1.1-28.6$ \\
\hline Total & 399 & 0 & 0.0 & $0.0-1.0$ & 7 & 1.8 & $0.9-3.6$ & 8 & 2.0 & $1.0-4.0$ & 22 & 5.5 & $3.1-7.5$ \\
\hline \multicolumn{14}{|l|}{ Females } \\
\hline $40-49$ & 129 & 0 & 0.0 & $0.0-3.1$ & 0 & 0.0 & $0.0-3.1$ & 2 & 1.6 & $0.5-5.8$ & 1 & 0.8 & $0.1-4.5$ \\
\hline $50-59$ & 86 & 0 & 0.0 & $0.0-4.7$ & 0 & 0.0 & $0.0-4.7$ & 0 & 0.0 & $0.0-4.7$ & 1 & 1.2 & $0.2-6.9$ \\
\hline $60-69$ & 84 & 1 & 1.2 & $0.2-7.0$ & 1 & 1.2 & $0.2-7.0$ & 0 & 0.0 & $0.0-4.8$ & 4 & 4.8 & $2.0-12.7$ \\
\hline $70-79$ & 110 & 3 & 2.7 & $1.0-8.3$ & 3 & 2.7 & $1.0-8.3$ & 5 & 4.5 & $2.1-10.9$ & 10 & 9.1 & $3.7-14.5$ \\
\hline $80+$ & 35 & 1 & 2.9 & $0.6-17.9$ & 7 & 20.0 & $6.7-33.3$ & 0 & 0.0 & $0.0-12.2$ & 4 & 11.4 & $0.9-22.0$ \\
\hline Total & 444 & 5 & 1.1 & $0.5-2.7$ & 11 & 2.5 & $1.4-4.5$ & 7 & 1.6 & $0.8-3.3$ & 20 & 4.5 & $3.0-7.0$ \\
\hline \multicolumn{14}{|l|}{ Total } \\
\hline 40-49 & 257 & 0 & 0.0 & $0.0-1.5$ & 0 & 0.0 & $0.0-1.5$ & 2 & 0.8 & $0.2-2.9$ & 5 & 1.9 & $0.9-4.6$ \\
\hline $50-59$ & 182 & 0 & 0.0 & $0.0-2.2$ & 0 & 0.0 & $0.0-2.2$ & 1 & 0.5 & $0.1-3.2$ & 3 & 1.6 & $0.6-4.9$ \\
\hline $60-69$ & 154 & 1 & 0.6 & $0.1-3.8$ & 1 & 0.6 & $0.1-3.8$ & 0 & 0.0 & $0.0-2.6$ & 7 & 4.5 & $1.9-8.7$ \\
\hline $70-79$ & 192 & 3 & 1.6 & $0.6-4.7$ & 5 & 2.6 & $1.2-6.2$ & 10 & 5.2 & $3.0-9.7$ & 21 & 10.9 & $6.1-14.7$ \\
\hline $80+$ & 58 & 1 & 1.7 & $0.3-10.4$ & 12 & 20.7 & $10.3-31.1$ & 2 & 3.4 & $1.1-13.3$ & 5 & 8.6 & $1.4-15.8$ \\
\hline Total & 843 & 5 & 0.6 & $0.3-1.4$ & 18 & 2.1 & $1.4-3.4$ & 15 & 1.8 & $1.1-2.9$ & 42 & 5.0 & $3.4-6.3$ \\
\hline
\end{tabular}

Blindness: best-corrected VA $>1.3 \log$ MAR (equivalent of $<20 / 400$ ) or a visual field $<10^{\circ}$ around central fixation; low vision: best-corrected VA $>0.5$ to $1.3 \log$ MAR (equivalent of $<20 / 70$ to $20 / 400$ ) or a visual field $<20^{\circ}$ to $10^{\circ}$ around central fixation.

Binocular impairment was defined based on findings in the better eye; monocular impairment was defined based on findings in the affected eye (VA in the fellow eye being normal or near-normal). 
data could not be obtained from four uncooperative subjects. We found 23 subjects with some degree of better eye visual loss (blindness or low vision) and 57 with monocular impairment. There were no significant gender-related differences in the prevalence figures for any of the age groups. The prevalence rates for better eye and monocular impairment both increased with age, particularly after the age of 70 . In total, 14 of the 80 visually impaired patients ( $1 / 5$ with better eye blindness, $5 / 18$ with better eye low vision, $4 / 42$ with monocular low vision, and 4 / 15 with monocular blindness) had normal or near-normal best-corrected VAs: their impairment was the result of visual field losses.

The picture that emerged from our analysis of bestcorrected visual status worsened considerably when we considered the presenting VAs of the subjects examined (Table 2). On the whole, only $80 / 843(9.5 \%)$ patients would have had some degree of better eye or monocular visual loss if optimally corrective lenses had been used, but in real life 177/843 (21.0\%) were conducting their activities under impaired visual conditions, using either lenses that were inadequate / inappropriate for their impairment or no form of correction at all. In the categories of low vision, the prevalence of presenting better eye impairments was three times as high as that based on best-corrected findings.

All 36 of the subjects, whose better eye visual status worsened when presenting VAs were considered, had undergone ophthalmologic examinations at some time prior to our study. In 18 cases (50\%), the previous examination had revealed no need for corrective lenses. In the other 18, lenses had been prescribed, but only four of these subjects (22\%) were using them, and in all four cases the correction was inadequate for the current degree of refractive error. The remaining 14 (78\%) were not using any type of corrective lenses for the following reasons: (1) they recognized the inadequacy of the old

Table 2 Prevalence of blindness and low vision according to best-corrected and presenting VA in the Ponza 2000 Eye Study

\begin{tabular}{lrrrrr}
\hline Visual loss & \multicolumn{2}{c}{ Best-corrected VA } & & \multicolumn{2}{c}{ Presenting VA } \\
\cline { 2 - 3 } \cline { 6 - 7 } & No. & $\%(95 \%$ CI $)$ & & No. & $\%(95 \%$ CI $)$ \\
\hline $\begin{array}{l}\text { No Impairment } \\
\text { Better eye }\end{array}$ & 767 & $91.0(89.1-92.9)$ & & 670 & $79.5(76.8-82.2)$ \\
$\quad$ Blindness & 5 & $0.6(0.3-1.4)$ & & 7 & $0.8(0.4-1.7)$ \\
$\quad$ Low vision & 18 & $2.1(1.4-3.4)$ & & 52 & $6.2(4.5-7.8)$ \\
Monocular & & & & & \\
$\quad$ Blindness & 15 & $1.8(1.1-2.9)$ & & 22 & $2.6(1.7-4.0)$ \\
$\quad$ Low vision & 42 & $5.0(3.4-6.3)$ & & 96 & $11.0(9.2-13.5)$ \\
All impaired & 80 & $9.5(7.5-11.5)$ & & 177 & $21.0(18.2-23.7)$ \\
\hline
\end{tabular}

prescription $(6 / 14 ; 43 \%)$; (2) they felt that the correction was unnecessary and that their uncorrected VA was sufficient for the activities they were engaged in (29\%); (3) they felt that glasses had a negative impact on their appearance $(14 \%)$; (4) they did not have time to buy the glasses prescribed since there are no optical stores on the island (14\%).

After stepwise logistic regression analysis and adjustment for the significant variables analyzed individually, the following emerged as significant risk factors for binocular visual loss (in decreasing order of importance): cataract (OR 12.3, 95\% CI 2.0-78.7), AMD (OR 11.5, 95\% CI 1.8-73.0), glaucoma (OR 7.2, 95\% CI 1.6-15.1), age $\geq 70$ (OR 7.0, 95\% CI 1.0-49.5), and, to a lesser extent, unmarried status (OR 2.5, 95\% CI 0.9-7.0).

Table 3 shows the causes of visual loss based on bestcorrected VAs. The main cause of better eye impairment per person (left side of Table 3) was unoperated cataract (34.8\%), followed by glaucoma (21.7\%), degenerative myopia (13.0\%), and AMD (8.7\%). The causes of better eye blindness were degenerative myopia (two cases), followed by unoperated cataract, retinitis pigmentosa, and the combination of AMD in one eye and nonglaucomatous optic-nerve atrophy in the other eye (one case). Monocular visual impairment was caused primarily by unoperated cataracts $(36.8 \%)$ followed by amblyopia (15.8\%), glaucoma (14.0\%), and diabetic retinopathy $(8.8 \%)$. When data were analysed according to the number of impaired eyes (right side of Table 3), unoperated cataract $(27.8 \%)$ remained the main cause of blindness followed by glaucoma (22.2\%), degenerative myopia (13.9\%), and AMD (8.3\%); cataract was even more important among the causes of low vision per eye (44.8\%), followed by glaucoma (16.4\%), amblyopia (11.9\%), diabetic retinopathy (7.5\%), and AMD (6.0\%).

\section{Discussion}

The data presented in this paper were collected in the municipality of Ponza, an island community with an official population of around 3500 persons. Like many small towns located in the coastal (and noncoastal) areas of the Italian peninsula, Ponza's economy is based largely on the tourist industry. In terms of ophthalmologic healthcare, Ponza is also reasonably representative of other small Italian communities. An ophthalmologist sees patients two days a month in the Local Public Health Department, where equipment is limited to the bare essentials (eg, there is no visual-field analyzer). There are no private ophthalmologic practices on the island. More complete public healthcare (inpatient and outpatient) is available in the hospital in Formia, which can be reached by hydrofoil or ferry in 
Table 3 Causes of visual loss per person and per eye in the Ponza 2000 Eye Study

\begin{tabular}{|c|c|c|c|c|c|c|c|c|c|c|}
\hline & \multicolumn{4}{|c|}{ Causes per person } & \multicolumn{6}{|c|}{ Causes per eye } \\
\hline & \multicolumn{2}{|c|}{ Better eye } & \multicolumn{2}{|c|}{ Monocular } & \multicolumn{2}{|c|}{ Blindness } & \multicolumn{2}{|c|}{ Low vision } & \multicolumn{2}{|c|}{ Total } \\
\hline & No. & $\%$ & No. & $\%$ & No. & $\%$ & No. & $\%$ & No. & $\%$ \\
\hline Central pterygium & - & - & 2 & 3.5 & - & - & 2 & 3.0 & 2 & 1.9 \\
\hline Corneal opacity & - & - & 2 & 3.5 & 1 & 2.8 & 1 & 1.5 & 2 & 1.9 \\
\hline Esotropia & - & - & 1 & 1.8 & 1 & 2.8 & - & - & 1 & 1.0 \\
\hline Glaucoma & 5 & 21.7 & 8 & 14.0 & 8 & 22.2 & 11 & 16.4 & 19 & 18.4 \\
\hline Cataract & 8 & 34.8 & 21 & 36.8 & 10 & 27.8 & 30 & 44.8 & 40 & 38.8 \\
\hline Amblyopia & - & - & 9 & 15.8 & 1 & 2.8 & 8 & 11.9 & 9 & 8.7 \\
\hline Myopia & 3 & 13.0 & 2 & 3.5 & 5 & 13.9 & 3 & 4.5 & 8 & 7.8 \\
\hline AMD & 2 & 8.7 & 1 & 1.8 & 3 & 8.3 & 4 & 6.0 & 7 & 6.8 \\
\hline Diabetic retinopathy & - & - & 5 & 8.8 & - & - & 5 & 7.5 & 5 & 4.9 \\
\hline Retinal detachment & - & - & 3 & 5.3 & 1 & 2.8 & 2 & 3.0 & 3 & 2.9 \\
\hline Retinitis pigmentosa & 1 & 4.3 & - & - & 2 & 5.6 & - & - & 2 & 1.9 \\
\hline Optic atrophy & - & - & - & - & 2 & 5.6 & - & - & 2 & 1.9 \\
\hline Macular hole & - & - & 1 & 1.8 & - & - & 1 & 1.5 & 1 & 1.0 \\
\hline Trauma & - & - & 2 & 3.5 & 2 & 5.6 & - & - & 2 & 1.9 \\
\hline Cataract, one eye, glaucoma, other eye & 1 & 4.3 & - & - & & & & & & \\
\hline Cataract, one eye, AMD, other eye & 1 & 4.3 & - & - & & & & & & \\
\hline Cataract, one eye, optic atrophy, other eye & 1 & 4.3 & - & - & & & & & & \\
\hline AMD, one eye, optic atrophy, other eye & 1 & 4.3 & - & - & & & & & & \\
\hline Total & 23 & 100.0 & 57 & 100.0 & 36 & 100.0 & 67 & 100.0 & 103 & 100.0 \\
\hline
\end{tabular}

1-2 h. Emergency cases are transported to this hospital by helicopter.

In this community, the overall prevalence rates in Ponza for best-corrected blindness and low vision were, respectively, 0.6 and $2.1 \%$; corresponding rates for presenting impairments were 0.8 and $6.2 \%$. It is possible that all these figures underestimate the actual prevalence of visual problems. Furthermore, the study was underpowered to provide age-specific estimates below 70 years of age. On the average, the patients we did not examine were significantly older than those of the participant group. Furthermore, a significant percentage (39\%) of those who declined to participate in the study did so because of 'health problems,' and the likelihood of visual problems among this category of nonparticipants might be relatively high.

On the whole, however, our age-specific prevalence rates are fairly consistent with those most recently published for Italy and other European countries with similar socio-economic conditions, in which eye-care expenses are covered to a large extent by public healthcare systems (Table 4). The Ponza 2000 figures shown in the table have been re-elaborated to reflect the specific population age range and the criteria used to define visual loss (US vs WHO definitions) in each comparison study. As far as best-corrected VA data were concerned, one of the main differences that emerged was a significantly higher prevalence of total visual loss (defined by US criteria) in the UK documented in 2000 by the National Diet and Nutrition Survey (22.4\%), with respect to that of Ponza $(11.8 \%, P<0.001)$. It should be noted, however, that in this survey all participants were examined in their homes. As the authors themselves point out, this factor may have resulted in the selection of a relatively fragile population sample, and the nonstandardized lighting conditions of the examinations may also have contributed to the high figures that emerged.

In contrast, the prevalence rates for WHO-defined low vision and US-defined blindness among subjects 55 and over in the Rotterdam Study were both significantly lower than those of Ponza. In all probability both these differences are related to the frequencies in the two populations of blindness associated with unoperated cataract (Ponza: $58.8 \%$ vs Rotterdam: $36.5 \%$; $P<0.001$ ) or glaucoma (Ponza: $17.6 \%$ vs Rotterdam: $1.6 \%$; $P=0.024$ ).

The former condition was, in fact, the main cause of better eye visual loss in Ponza. Cataract surgery would have eliminated over half $(12 / 22)$ of the WHO-defined cases of better eye visual loss, reducing the prevalence of blindness by one-fifth (from 0.6 to $0.5 \%$ ) and that of low vision by two-thirds (from 2.1 to $0.7 \%$ ). Only one of the twelve subjects in question was under 70, and most (7/12) were 80 or older. As our presenting VA analysis shows, Italians in this age group are particularly likely to neglect visual loss, even when it can be eliminated by means of corrective lenses. In the case of cataract, our experience indicates that failure to seek surgical 
Table 4 Comparison between age-specific prevalence rates of visual loss in the most recent European studies

\begin{tabular}{|c|c|c|c|c|c|c|c|c|c|}
\hline \multicolumn{7}{|c|}{ Previous European prevalence studies } & \multicolumn{3}{|c|}{ Ponza 2000 Eye Study } \\
\hline Study & Country & $\begin{array}{l}\text { Age } \\
\text { (years) }\end{array}$ & Criteria & $\begin{array}{l}\text { Sample } \\
\text { size }\end{array}$ & $\begin{array}{c}\% \\
\text { Blindness }\end{array}$ & $\begin{array}{l}\% \text { Low } \\
\text { vision }\end{array}$ & $\begin{array}{l}\text { Sample } \\
\text { size }\end{array}$ & $\begin{array}{c}\% \\
\text { Blindness }\end{array}$ & $\begin{array}{l}\text { \% Low } \\
\text { vision }\end{array}$ \\
\hline $\begin{array}{l}\text { Casteldaccia Eye Study, } \\
1994\end{array}$ & Italy & $40-79$ & WHO & 1068 & 0.5 & 1.2 & 785 & 0.5 & 0.8 \\
\hline Oulu County Study, 1995 & Finland & $70+$ & WHO & 476 & 1.9 & 10.8 & 250 & 1.6 & 6.8 \\
\hline Rotterdam Study, 1998 & The Netherlands & $55+$ & WHO & 6775 & 0.5 & 1.4 & 492 & 1.0 & 3.7 \\
\hline $\begin{array}{l}\text { National Diet and } \\
\text { Nutrition Survey, } 2000\end{array}$ & United Kingdom & $65+$ & WHO & $1126^{\mathrm{a}}$ & \multicolumn{2}{|c|}{9.9} & 329 & \multicolumn{2}{|c|}{6.7} \\
\hline $\begin{array}{l}\text { Copenhagen City Eye } \\
\text { Study, } 2001\end{array}$ & Denmark & $60-80$ & $\mathrm{WHO}$ & 944 & 0.5 & 1.9 & 354 & 1.1 & 1.7 \\
\hline MRC Trial, 2002 & United Kingdom & $75+$ & WHO & 14600 & 2.1 & 10.3 & 147 & 2.0 & 10.9 \\
\hline Rotterdam Study, 1998 & The Netherlands & $55+$ & US & 6775 & 0.8 & 3.8 & 492 & 2.4 & 4.7 \\
\hline $\begin{array}{l}\text { National Diet and } \\
\text { Nutrition Survey, } 2000\end{array}$ & United Kingdom & $65+$ & US & $1126^{\mathrm{a}}$ & \multicolumn{2}{|c|}{22.4} & 329 & \multicolumn{2}{|c|}{8.2} \\
\hline $\begin{array}{l}\text { Copenhagen City Eye } \\
\text { Study, } 2001\end{array}$ & Denmark & $60-80$ & US & 944 & 1.1 & 3.4 & 354 & 1.7 & 1.7 \\
\hline MRC Trial, 2002 & United Kingdom & $75+$ & US & 14600 & \multicolumn{2}{|c|}{19.9} & 147 & \multicolumn{2}{|c|}{15.6} \\
\hline $\begin{array}{l}\text { North London Eye survey, } \\
1998\end{array}$ & United Kingdom & $65+$ & $\mathrm{US}^{\mathrm{b}}$ & 1547 & \multicolumn{2}{|c|}{30.2} & 329 & \multicolumn{2}{|c|}{16.1} \\
\hline
\end{tabular}

${ }^{\mathrm{a} C}$ Community sample only.

bresenting visual loss.

$P$-values assessed with the $\chi^{2}$ test.

WHO criteria - Low vision: Rotterdam (1.4\%) vs Ponza $2000(3.7 \%), P<0.001$.

US criteria - Blindness: Rotterdam (0.8\%) vs Ponza 2000 (2.4\%), $P<0.001$; best corrected blindness + low vision: NDTS (22.4\%) vs Ponza 2000 (8.2\%), $P<0.001$; presenting blindness + low vision: North London (30.2\%) vs Ponza $2000(16.1 \%), P<0.001$.

treatment (which is fully covered under the National Healthcare System in Italy) is primarily related to the perceived risks associated with surgery and / or the 'inconvenience' associated with even a brief hospitalization (Cedrone, unpublished data).

The only study in Table 4 that provides data on presenting visual loss is the North London Eye Survey, which examined a large sample of subjects 65 and over. The prevalence of US-defined visual loss in general (ie, blindness or low vision) was over $30 \%$ - almost twice as high as that of our 65-and-over age group. In both cases, however, substantial portions of the elderly population of two of the world's most highly developed nations appear to be operating under conditions of more or less severe visual loss, which in most cases could be eliminated.

The vast majority $(25 / 36)$ of discrepancies between best-corrected and presenting VAs in Ponza were due to uncorrected or miscorrected refractive errors, which were the second cause of presenting visual loss reported in the North London Eye Study. Relatively few of the subjects we examined cited inaccessibility of optical stores as a justification for their failure to use optimally corrective lenses. While it is true that the islanders have to travel to the continent to purchase glasses, they are quite accustomed to trips of this sort, and the ferries are used much like buses and subways. The situation in
Ponza is really no different from that of any other small Italian town on the continent, where citizens often have to travel to other municipalities to purchase various goods. The high prevalence of presenting impairments in North London, where opticians are likely to be much more accessible, further confirms the relative unimportance of this factor. Economic considerations were cited even more rarely in our study. Eye examinations are provided free of charge through the National Healthcare Service for all citizens 65 or older.

In conclusion, the tendency to consider suboptimal VA 'a normal part of aging' or 'sufficient for one's daily activities' appears to be widespread. It is possible that greater emphasis needs to be placed on patient education during eye examinations: the patient must be made to understand the value of good visual acuity (even during the later stages of life, when physical activity may be reduced) and the importance of regular follow-up examinations to adjust lens prescriptions.

Finally, our figures on presenting impairments seem to confirm the reliability of the findings that emerged from the most recent NHHS for Italian citizens aged 45 and over. The self-reported rates of perceived blindness in this survey $(0.3 \%$ for ages $45-64 ; 1.09 \%$ for ages $65-74$ and $4.87 \%$ for persons aged 75 years) were fully compatible with the estimated rates of presenting blindness and low vision (WHO definitions) in the Ponza 
2000 study (respectively, $0.3 \%$ and $1.9 \%$ for ages $45-64$ (372 subjects), $0.5 \%$ and $5.5 \%$ for ages $65-74$ (183 subjects), and $3.4 \%$ and $21.1 \%$ for persons aged 75 years and over (147 subjects)). Moreover, almost $20 \%$ of the 48 low-vision cases (9/48) aged 45 years and over had a presenting VAs $\leq 1.0$ LogMar (20/200) in the better eye, and it is reasonable to assume that most or all these subjects would have admitted difficulty in seeing and recognizing a friend at a distance of four meters. The estimated rate of blindness found in the last NHHS probably provides a reasonably accurate picture of the problem of presenting blindness in Italy today. Our findings indicate that a substantial percentage of these problems can be eliminated with appropriate medical or surgical therapy or optimal correction of refractive errors and suggest that greater emphasis needs to be placed on educating the public regarding the importance of good vision.

\section{Acknowledgements}

This research was supported in part by the contribution of the Italian MIUR - Ministry of Instruction, University and Research -1998-2000, Project no. 9806216964.

\section{References}

1 Thylefors B, Nègrel AD, Pararajasegaram R, Dadzie KY. Available data on blindness (update 1994). Ophthalmic Epidemiol 1995; 2: 5-39.

2 Hirvela H, Laatikainen L. Visual acuity in a population aged 70 years or older; prevalence and causes of visual impairment. Acta Ophthalmol Scand 1995; 73: 99-104.

3 Klaver CC, Wolfs RC, Vingerling JR, Hofman A, de Jong PTVM. Age-specific prevalence and causes of blindness and visual impairment in an older population: the Rotterdam Study. Arch Ophthalmol 1998; 116: 653-658.
4 Buch H, Vinding T, La Cour M, Nielsen NV. The prevalence and causes of binocular and monocular blindness in an elderly urban Danish population. The Copenhagen City Eye Study. Acta Ophthalmol Scand 2001; 79: 441-449.

5 Buch H, Vinding T, Nielsen NV. Prevalence and causes of visual impairment according to World Health Organization and United States criteria in an aged, urban Scandinavian population: the Copenhagen City Eye Study. Ophthalmology 2001; 108: 2347-2357.

6 Evans JR, Fletcher AE, Wormald RPL, Siu-Woon Ng E, Stirling S, Smeeth L et al. Prevalence of visual impairment in people aged 75 years and older in Britain: results from the MRC trial of assessment and management of older people in the community. Br J Ophthalmol 2002; 86: 795-800.

7 Reidy A, Minassian DC, Vafidis G, Joseph J, Farrow S, Wu J et al. Prevalence of serious eye disease and visual impairment in a north London population: population based, cross sectional study. BMJ 1998; 316: 1643-1646.

8 van der Pols JC, Bates CJ, McGraw PV, Thompson JR, Reacher M, Prentice A et al. Visual acuity measurements in a national sample of British elderly people. $\mathrm{Br} \mathrm{J} \mathrm{Ophthalmol}$ 2000; 84: 165-170.

9 Zapelloni A, Rossi T, Sotis G, Lambiase A, Nucci C, Sabatini $\mathrm{L}$ et al. Indagine preliminare sulla prevalenza delle minorazioni visive e le loro cause a Priverno. Boll Ocul 1993; 72: 993-1002.

10 Ponte F, Giuffrè G, Giammanco R. Prevalence and causes of blindness and low vision in the Casteldaccia Eye Study. Graefes Arch Clin Exp Ophthalmol 1994; 232: 469-472.

11 Cedrone C, Zapelloni A, Cesareo M, Trematerra M, Corsi A, Cerulli L. Prevalenza delle minorazioni visive e loro cause in popolazioni definite dei comuni di Ponza e Priverno. Minerva Oftalmol 1997; 39: 67-71.

12 ISTAT-Istituto Nazionale di Statistica. Indagine multiscopo sulle famiglie. 'Condizioni di salute e ricorso ai servizi sanitari' Anni 1999-2000. Roma, Italia, 2002.

13 Nucci C, Cedrone C, Culasso F, Ricci F, Cesareo M, Corsi A et al. Incidence of visual loss in the Ponza Eye Study, Italy. Eye 2005; 19(2): 175-182.

14 Ricci F, Cedrone C, Cerulli L. Standardized measurement of visual acuity. Ophthalmic Epidemiol 1998; 5: 41-53. 